\title{
CareerSolutions@10 Android Application
}

\author{
Nandana Prabhu \\ Dept of Information \\ Technology \\ KJSCE \\ Vidyavihar
}

\author{
Aditya Somaiya \\ Dept of Information \\ Technology \\ KJSCE \\ Vidyavihar
}

\author{
Dhwani Shah \\ Dept of Information \\ Technology \\ KJSCE \\ Vidyavihar
}

\author{
Poonam Yadav \\ Dept of Information Technology \\ KJSCE \\ Vidyavihar
}

\author{
Janvi Rajani \\ Dept of Information Technology \\ KJSCE \\ Vidyavihar
}

\begin{abstract}
The students who have appeared for standard $10^{\text {th }}$ have to make decision regarding their future as soon as their exams are over. There are many parameters which can influence the decision of the student. In such a situation, there are chances that students land up taking wrong decision. There are various centers which organize aptitude test which can help the student in deciding their career. But going to the center for the test is again time consuming and inconvenient at times. Moreover, the admission process for seeking admission in junior college is also tedious. The students are sometimes unable to fill their form for preference of colleges. Today, the smart phones have replaced desktop, personal computer's and laptops in many ways. This paper provides an android application as a solution to the above problem. This application will act as a guidance tool to seek admission in good colleges according to their area of interest. The aptitude test will guide them in choosing their field and a Global Positioning System(GPS)which will guide them in selecting good colleges.
\end{abstract}

\section{Keywords}

Android; Aptitude; Test; Login; Aptitude test; Result Evaluation; College Location; Roadmap Generation

\section{INTRODUCTION}

Today mobiles are an integral part of daily life. With time, customers are expecting best and very versatile applications in less time. The advancement in mobile technology has improved everyone's life. Various applications are used in day to day life to reduce the load of work in some way or the other. The students who have appeared for Secondary School Certificate(SSC) Exams have to decide their field of interest. For this they have to go to different counseling centers to give Aptitude test, after the test is done the student has to go to the centre again to collect their result. The counselor does not help the student to select the colleges to be filled. Moreover, these sessions are chargeable. A good number of mobile applications are available for giving mock tests. But there is no application that provides all of this under one roof. One solution to this is to have an application in mobile for guiding the students.

Android technology is chosen as it is freely downloadable. Moreover, with enhanced data storage (using SQLite framework) which occupies less space, has increased the number of people using android technology.

\section{EXISTING SYSTEM}

Currently in the Indian system, to give an aptitude test the student has to go to a particular centre for the test. Students usually get guidelines from their parents, family, relatives, friends, etc based on their experience. This gives them limited choice in choosing the field for their career. They are also influenced by current trends, reviews, etc. The evaluation of the aptitude test is also done manually which may lead to error. Moreover, the students face lot of difficulties during the process of selecting colleges as the process is online.

\section{LITERATURE REVIEW}

Today education technology is constantly growing and is also offering interesting features for learning environment. In [1], the authors have provided the comparison between the previously developed E-learning systems for desktop and laptop and today's new E-learning applications which can be used anywhere anytime though Smart phones. The application developed by them is mainly used for testing the knowledge level of students in the class room or for candidate appearing for some placement papers. According to them this application can be further used for recruitment process which will save a lot of time. Also there are applications which help the students to prepare placements and competitive exams like GRE, GMAT, GATE. In [2], the authors have described about their application which lets the students prepare for such exams by attempting mock tests provided in it. This application also encourages them to search the required study material by themselves from different resources. The authors have thanked today's Smartphone technology which allow its users to learn faster and in more efficient way. CareerSolutions@10 is an application which is used to guide SSC students with the help of aptitude test.

This will suggest the students their area of interest based on the aptitude test

It is also observed that students find it difficult to select colleges while filling the online application form for selecting preference of colleges. CarerSolutions@10 also gives the directions to reach that particular college. This requires location based services. In [3] the authors have discussed about the location based information system which is used to aid with the accurate information, at right place in real time with personalized setup and location sensitiveness. They have described the requirements of Android Application that is Android operating system, GPS Technology, Java Technology(J2EE). According to the authors, Location-Based Service(LBS) is a mobile application that is dependent on the 
location of a mobile device. They used a positioning component which is usually needed in LBS application to determine the location of user's mobile device. In [4], the authors have discussed about Location based Services offered to the mobile users to retrieve information about their current location and process that data to get more useful information near to their location. They discussed about different location based services like current traffic conditions, providing routing information etc. They implemented Location based services through Google Web Services and Walk Score Transit APIs on Android Phones to give multiple services to their user based on their Location.

\section{PROPOSED SYSTEM}

By considering the limitations of the existing system, CareerSolution@10 has been developed to cover all the features and overcomes the cons of the already existing system. By keeping in mind the Student's need, this application consists of two sections - Aptitude test and College locator.

The features provided are:

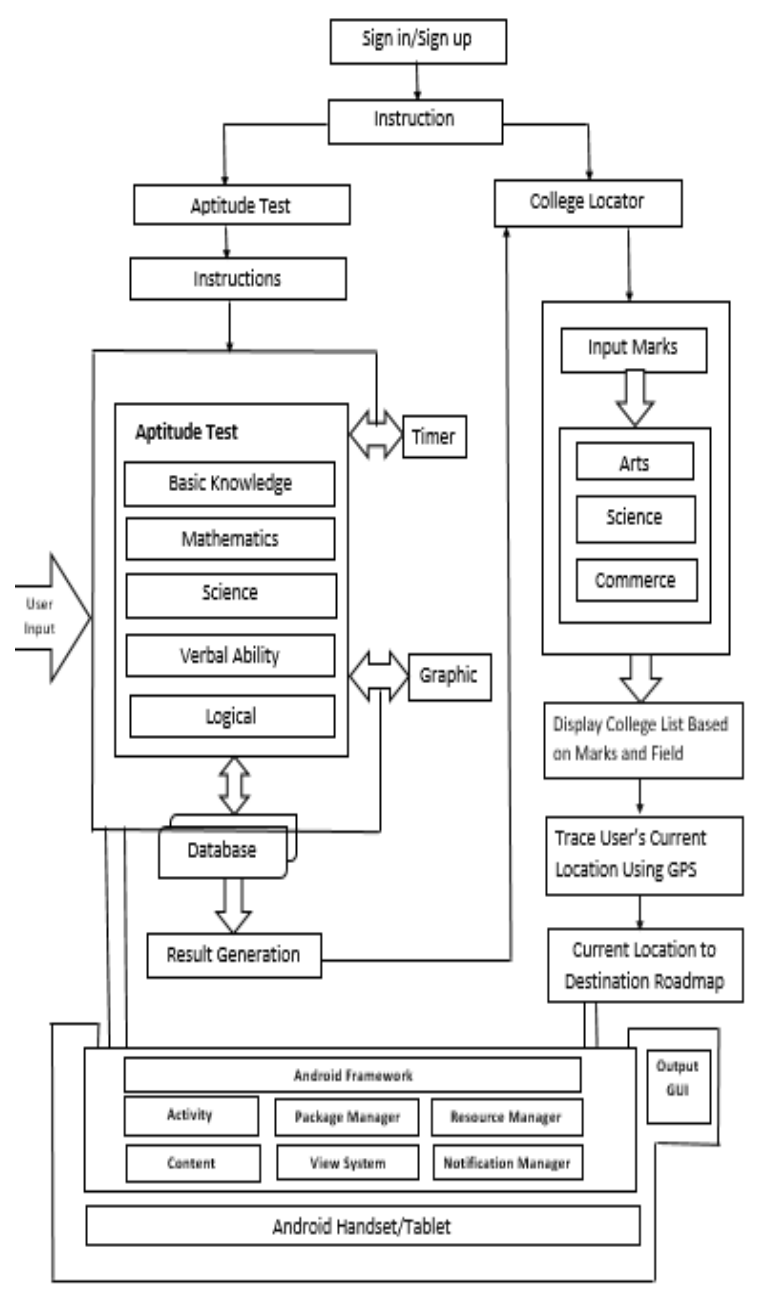

Figure 1: System Architecture of CareerSolutions@10 Application

\subsection{Aptitude test:}

This module contains 5 sections and each section contains 20 questions and their correct answers will be stored in the database. The students will be able to answer the questions according to their choice.

\subsection{Instructions}

This option provides the instructions of how to use this application and how to navigate through different pages.

\subsection{Timer}

A timer is set for an hour and students have to attempt the questions within the given timeframe. The students can attempt the test in any order of sections but attempting all sections is must. The student can also finish the section before time elapses.

\subsection{Aptitude Test Evaluation}

The student has to attempt all the sections. Depending on the type of questions attempted by the student and the number of questions correctly answered by the student a result will be generated as to which field he/she should select.

\subsection{College Locator}

The student will have to enter their marks, preferred field and location. List of colleges will be displayed according to the cut-off.

\subsection{College Roadmap}

The student will get to see the roadmap of the selected college.

\section{SYSTEM DESIGN \\ 5.1 Use Case Diagram}

A Use Case diagram is used to represent the actions by the user in a system. It has roles and actions. Users can have personal access to the application and can perform different actions. For the CareerSolutions@10 Android application, User can perform the following actions

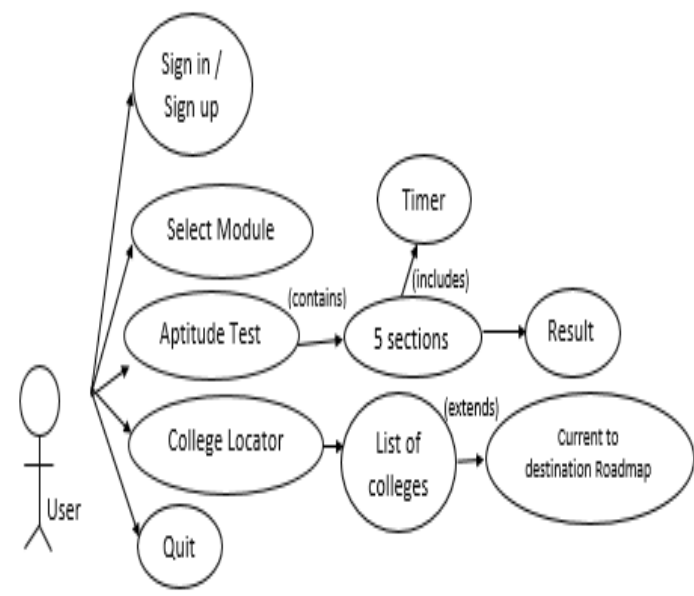

Figure 2:Use Case Diagram of CareerSolutions@10

\section{IMPLEMENTATION}

When the student starts the application, the main screen is loaded with the login module [18]. The new student will have to create an account and existing students have to sign in. The student will get a set of instruction about the application. The student will then see two options Aptitude Test and College Locator. The student has to select any one. If the user selects the Aptitude test he/she will see 5 sections. They can attempt the test in any order of the sequence. The test is time based so the students will have to complete the test within 60 minutes. Each section contains 20 questions. The user has to finish the test before the time elapses and submit it. If the time is up and 


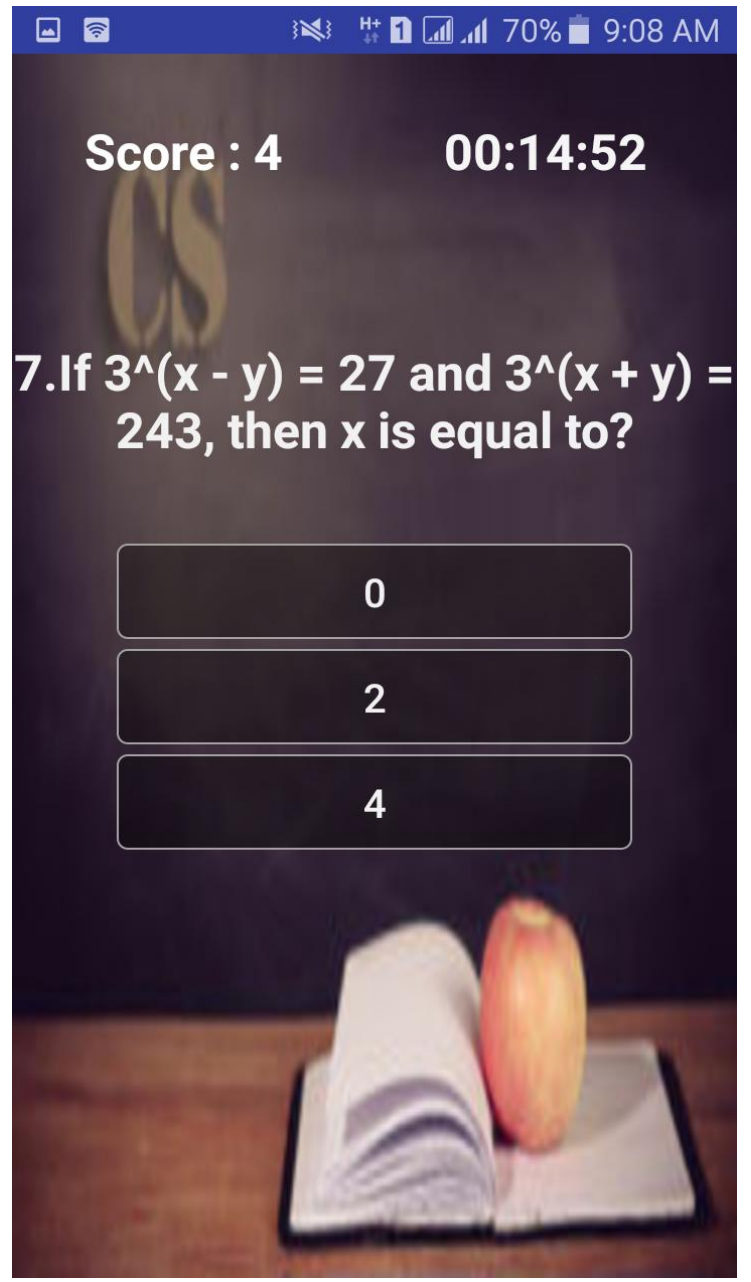

Figure 5: UI of Aptitude Test

\subsection{Timer}

CareerSolution@10 provides timer for Aptitude test which lets the student to complete the test in 60 minutes.

\subsection{Result Evaluation}

The result evaluation of the aptitude test is manually done in the existing system which might lead to error.

CareerSolution@10 evaluates the test depending on the number of question attempted in a particular section and the number of questions correctly answered in that section

The field is generated on the basis of the basis necessary requirement of that field. The factors like Intelligence quotient, Emotional Intelligence, Family Background, etc are not taken into consideration.

\subsection{Result Generation}

The Student has to go to the particular centre tocollect their result.CareerSolution@10 provides the result of the online aptitude test as soon as the student clicks the Submit button. This will save the students time and efforts.

\subsection{Two in One Application}

The CareerSolution@10 allows the students to select from the Aptitude Test and College Locator Module.

This is right now not available in the actual existing system.

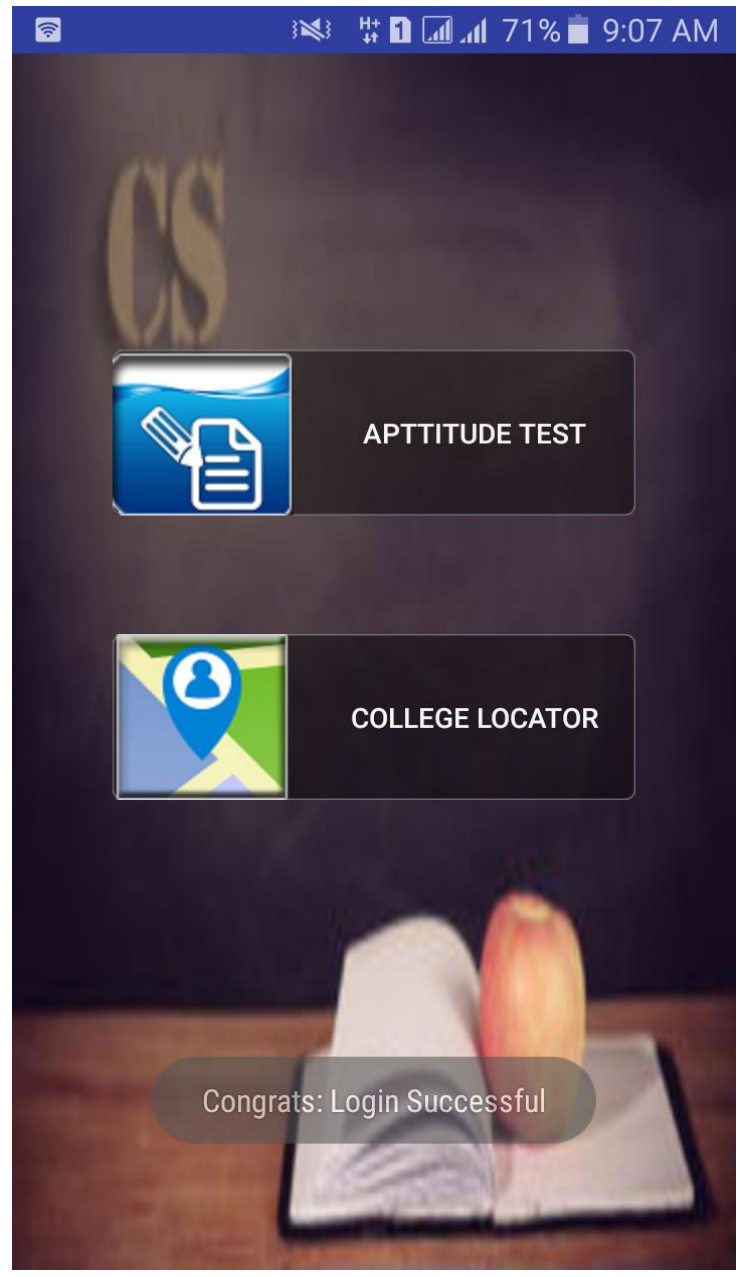

Figure 6:Two in One Feature of CareerSolutions@10

\subsection{College locator}

The students have to add a list of preferred colleges when they fill the online admission form. When students enter their SSC marks and their field of interest a List of Colleges in Mumbai of the desired field will be displayed [10].

\subsection{Roadmap}

When student clicks on any college from the list then he/she can see the roadmap to from their current location towards that particular college on Google Maps. This will help student to reach to that college with great ease.

\section{CONCLUSION}

This research paper discusses about the fine points and flaws of the existing system. By considering the need of the students of tenth standard, this application has been developed in the most preferred mobile operating system i.e. Android. The application developed is user-friendly \& low-cost Android Application for guiding students for deciding their field of interest. The target users of this application will be the students of standard 10th. The students there by using this application will be able to give aptitude test, analyze result, search colleges on the basis of marks and required field and view roadmap of desired college.

\section{FUTURE SCOPE}

The student may require to perform some calculations, so a scratchpad can be provided in future. Also we can add module for getting notifications of the work to be done like filling 
form, updating details in the form, also the College Locator module can be further developed for state and country etc.

\section{ACKNOWLEGDEMENT}

Mr Aditya Somaiya, Ms. Dhwani Shah, Ms. Janvi Rajani, Ms. Poonam Yadav would like to thank Prof Mrs. Nandana Prabhu for her constant encouragement and help. Her guidance in understanding the various aspects related to this project was vital.

\section{REFERENCES}

[1] Prof. (Dr) Praveen Gupta, Mukesh Kumar, MeghaSharma, "Architecture for Mobile Quiz

Applicationusing Android Application Framework".International Journal of Computer Science,November 2014.

[2] Asst Prof. Nataasha Raul, Ruchika Shah, JinalShah, Priti Sane, "Student Guide: Offline AndroidApplication", International Journal of ComputerApplication, May 2014.

[3] Prof.Seema Vanjire, Umesh Kanchan, GaneshShitole, Pradnyesh Patil ," Location Based Serviceson Smart Phone Through the Android Application", International Journal of Advanced Research inComputer and Communication Engineering, Vol.3. Issue 1, January 2014.

[4] Prof.Manav Sangal, Anupam Shukla," Implementation Android using GPS and Web Services", International Journal of Computer Science Issues, Vol. 9, Issue 1, No. 2, January 2012.

[5] Aptitude Question, http://examtimequiz.com

[6] Question, www.indiabix.com

[7] Aptitude Question -www.eduzip.com

[8] Quiz Layout: https://www.developerfeed.com/simplequiz-game-andriod/
[9] Listviewofcollegehttp://www.androidhive.info/2011/10/a ndroid-listview-tutorial/

[10] Listviewofcollege,http://www.edumobile.org/android/lea rn-how-to-create-listview-from-sqlite-database-inandroiddevelopment/

[11] Help-https://www.quora.com

[12] Related Information, www.google.com

[13] Questions Available for Aptitude Test http://www.sawaal.com/aptitude-reasoning/verbalreasoning-mental-ability/direction-sense-test-questionsand-answers.html

[14] Error Handing, http://stackoverflow.com

[15] AndroidTutorialsReferredhttps://thenewboston.com/vide os.php?cat $=278$

[16] Aptitude Test modulehttp://www.parallelcodes.com/android-gametutorial/

[17] Reference for SQLite Database Connectivityhttp://www.101apps.co.za/index.php/articles /using-a-sqlite-database-in-android.html

[18] Login Module Development, http://kalisandroid.blogspot.in/2014/04/login-and registration-using-sqlite.html

[19] Website Referred for coding https://www.github.com

[20] Open Source Software used for Developing AndroidApplicationhttp://developer.android.com/sdk/ind ex.html 